Books, videos, CD-ROMs, DVDs and any other relevant items submitted for a review in the $B D J$ should be addressed to: Kate Maynard, Assistant Editor, British Dental Journal, NPG, 4-6 Crinan Street, London N1 9XW

\section{The treatment of edentulous patients}

\author{
J.F. McCord, P. Smith, N. Grey \\ UK: Elsevier Churchill Livingstone \\ price €29.99, pp124 \\ ISBN 0443073074
}

This short textbook of just over 100 pages is aimed at undergraduate dental students and those who have very recently qualified. The book is logically organised into eight chapters, the first six covering the steps involved in the provision of complete dentures. Chapter one comprehensively covers the 'assessment of edentulous patients' and this is complemented by chapter two covering 'treatment options'.

Throughout the book there are many excellent and clear illustrations. One feature I particularly liked was the informative tables that summarise salient points. These will enable students to quickly revise important points. Chapter four covers the 'registration stage' and this is probably the clearest explanation of this stage I have seen. It will be most welcome by students!

Chapter seven covers the technological aspects of denture construction concisely and clearly. The book ends with a series of eight case studies. These cover a good range of prosthetic treatments and common problems and include a discussion of the treatment options, although in one or two cases the detail is limited.

It is not, of course, possible to agree with everything in a dental textbook but I found myself agreeing with nearly all of the authors' statements. The only area I felt uncomfortable with was the authors' contention that replica denture systems are: 'demanding of clinical and technical skills' and 'not an easy option'. I believe the opposite to be true and personally I would often be lost without replica record blocks making life easy! There are a number of small typographical errors in the book and Figure 7.1 is used again as Fig. CS 7.1 in error.
Overall I feel this is a first rate book to add to the list of undergraduate texts. Certainly every dental student who wishes a lucid and well illustrated explanation of how to treat edentulous patients should buy one. It should also be of value to VT dentists, those studying for MFDS and any dentist who feels they need to revise this area of dentistry.

J.R. Drummond doi: 10.1038/sj.bdj.4812095

\section{Human disease for dentistry}

\author{
F. Fortune \\ UK: Oxford University Press \\ price $€ 29.95$, pp414 \\ ISBN 0192631632
}

The author of Human disease for dentistry is a highly respected clinician who has an impressive knowledge and understanding of general medicine and its relevance to all aspects of dentistry. This expertise is clearly demonstrated in this comprehensive text, which is aimed at helping dental undergraduates understand the significance of the patient's medical history and its potential impact on the dental management of the patient.

The text runs to some 414 pages and 17 chapters. The first chapter is a most useful introduction to patient assessment, and includes a brief overview on the issues of consent and negligence, topics that are often overlooked in student texts. This chapter concludes with a concise summary of trauma and shock. The subsequent chapters deal with human disease in a largely systematic fashion. To aid accessibility there are very helpful text boxes highlighting key facts and also the dental relevance of many of the topics discussed. In addition there is extensive use of bulleted text that will further increase the book's appeal particularly for revision purposes, although there are few diagrams and no clinical photographs. There are also very few cited references and no suggestions for further reading on the main topic areas.

If there is a criticism of this book it is that parts of the text seem unduly detailed and perhaps lacking in simple explanation for undergraduates. Such detail can, on occasion, detract from the salient features of the disease entities under consideration. Inevitably this is a consequence of trying to produce such a comprehensive text. This may also explain the inclusion of some esoteric topics that would normally be considered unwarranted at undergraduate level. Examples of these include anthrax infection, toxic shock syndrome and napkin psoriasis.

In summary, this book contains a wealth of material, and will be a useful addition to the sources of reference required for the human disease course for dental undergraduates. Equally it will also provide a valuable source of reference for junior hospital staff and those working in primary dental care and special needs dentistry.

J. Hamburger doi: 10.1038/sj.bdj.4812096

\section{Drug information} handbook for dentistry: oral medicine for medically-compromised patients and specific conditions

R.L. Wynn, T.F. Meiller, H.L. Crossley

USA: Lexi-Comp

price $\$ 43.95$, pp 1779

ISBN 159195102X

This $10^{\text {th }}$ edition dental drug reference text has three principal authors, two of whom are dentists, the third a 

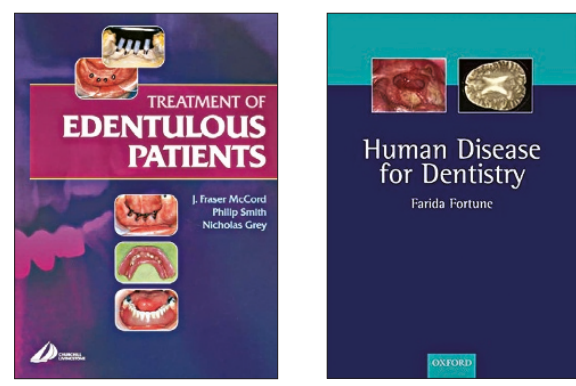

pharmacist, all based at the University of Maryland, Baltimore. In addition there are 71 people on the editorial panel, all based in the USA or Canada. In total the book runs to almost 1800 pages with the first 1400 pages detailing the drugs to be discussed in alphabetic order. This listing is followed by a brief (around 50 pages) evaluation and description of herbal and dietary supplements and natural products. Thereafter the oral medicine topics are divided into three parts: dental management and therapeutic consideration in the medicallycompromised; dental management and therapeutic consideration in patients with specific oral conditions; and other oral medicine topics. Under the heading of 'Appendices' are six sections dealing with standard conversions, calcium channel blockers and gingival hyperplasia, infectious disease information, laboratory values, over the counter dental products and miscellaneous. Clearly the book is written with a North American audience in mind but many of the principles expressed are relevant to European and indeed global dental practice.

The information relating to each drug is given in a standard format starting with the pronunciation of the drugs name. There then follows the US brand name, information on whether a generic drug is available, any synonyms by which the drug is known, pharmacologic category of drug (eg antineoplastic agent) and the condition(s) which the drug is used to treat. In a dental context there is then a highlighting of whether any local anaesthetic/vasoconstrictor precautions apply and whether the drug has an effect on dental treatment.

The text then highlights common adverse effects, the mechanism of action of the drug, drug interactions, the pharmacokinetics of the drug, risk in pregnancy, breast feeding considerations and finally dosage forms. For some drugs such as oral contraceptives additional information is given in relation to contradictions and warnings/precautions.
Overall the book undoubtedly contains a wealth of information and has been meticulously researched and written. It is valuable as a reference source and its value is enhanced by encompassing detailed information on natural products, herbal and dietary supplements.

P.J. Lamey
doi: $10.1038 /$ sj.bdj.4812097

Digital and

conventional dental radiography: a practical clinical

\section{manual}

\section{Ahmad (Ed) \\ UK: Quintessence \\ price $€ 52$, pp234 \\ ISBN 1867154365}

At a time when everybody is discussing digital photography, Irfan Ahmad has published a book mostly dealing with conventional photography; not with 'normal' dental photography, but with high-end techniques to achieve high-end results.

In Section 1 he begins with some common remarks on lighting, close-up photography and visual perception and also talks about the equipment, mentioning digital cameras. The fact that he does not show a single camera in this technical part proves that he is more interested in principal questions emphasising lighting techniques - than in technical details.

Section 2 is the main part of the book. In seven chapters (130 pages) the author discusses different photographic setups. Topics include facial compositions, natural dentition, anterior and posterior prostheses, periodontal and surgical procedures, dental pathology and dental laboratory. Clear drawings show the setup in principle; clinical pictures show
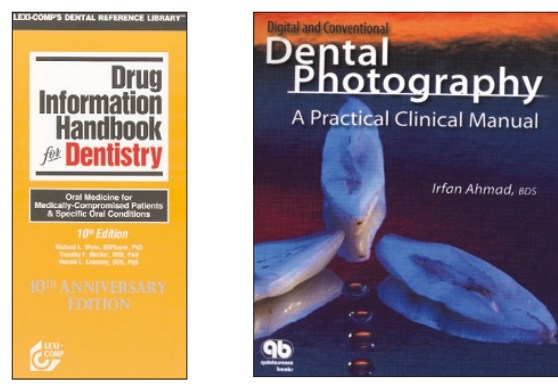

the results of these efforts. Unlike other authors, Ahmad recommends supporting the camera using a tripod during clinical photography. Lighting is performed with two light sources (or one light combined with a reflector) and usually two flashes with diffusors, placed at an angle to the object to produce shadows and a threedimensional effect.

Using this technique the author gets outstanding results: crisp pictures with high plasticity. But the technique is limited to anterior teeth. Only a few pictures of posterior teeth are shown. How the flashes are fixed remains unclear. In some cases they seem to be attached to the camera using a large bracket; in other cases they seem to be supported by tripods.

In one chapter the author shows in numerous cases how details like cracks or preparation margins are emphasised. His goal is to achieve a picture that is perfect from a photographic standpoint, not to get quick reproducible results.

Section 3 deals with image management, referring to conventional and digital images and editing and presentation techniques. This chapter is rather short and gives only an outline of these problems.

I would recommend Ahmad's book to all dentists and dental technicians who are advanced dental photographers and who are willing to spend far more effort than the usual point and shoot procedure. It is not a book dealing with all the basic techniques of dental photography or the latest developments of digital photography. It is a book showing how to get outstanding pictures if you have a passion for dental photography.

W. Bengel doi: 10.1038/sj.bdj.4812098 